\title{
Longitudinal fiber dysfunction assessed during cine-cardiac magnetic resonance imaging is an independent predictor of adverse cardiac events
}

\author{
Satish J Chacko ${ }^{1 *}$, Vibhav Rangarajan", Nikhil Jariwala', Simone Romano², Jaehoon Chung ${ }^{1}$, Afshin Farzaneh-Far ${ }^{1,3}$ \\ From 19th Annual SCMR Scientific Sessions \\ Los Angeles, CA, USA. 27-30 January 2016
}

\section{Background}

Left ventricular systole involves coordinated contraction of longitudinal, circumferential, and radial myocardial fibers. Longitudinal fiber dysfunction appears to be an early marker for a number of pathological states. We hypothesized that reduced mitral annular plane systolic excursion (MAPSE) measured during cine-Cardiac Magnetic Resonance (CMR) imaging reflects changes in longitudinal fiber function and may be an early marker for adverse cardiovascular outcomes.

\section{Methods}

400 consecutive patients with known or suspected coronary artery disease undergoing CMR were prospectively enrolled. Lateral MAPSE was measured in the 4chamber cine view by two independent observers. Patients were prospectively followed for major adverse cardiac events (MACE) - death, non-fatal myocardial infarction, hospitalization for heart failure or chest pain, and late revascularization. Cox proportional hazards regression modeling was used to identify factors independently associated with MACE.

\section{Results}

The mean age of the study population was $58( \pm 15)$ years, with a mean ejection fraction of $59( \pm 14 \%)$. $31 \%$ of the individuals had known coronary artery disease and $33 \%$ were diabetic. 72 MACE occurred during a median follow-up of 14.5 months. By Kaplan-Meier analysis, patients with lateral MAPSE $\leq 1.11 \mathrm{~cm}$ (median) experienced significantly higher incidence of MACE than patients with a MAPSE $>1.11 \mathrm{~cm}(\mathrm{p}=0.0270)$

${ }^{1}$ Cardiology, University of Illinois at Chicago, Chicago, IL, USA Full list of author information is available at the end of the article

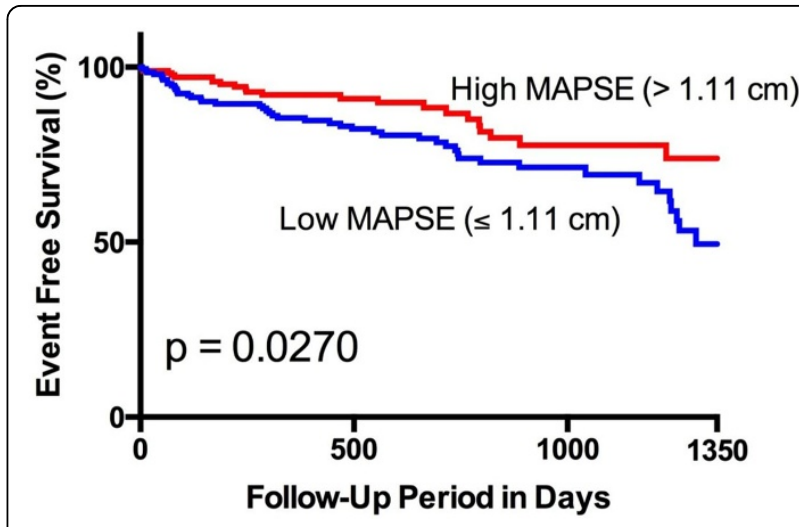

Figure 1 Kaplan-Meier curves for MACE in patients with MAPSE above and below the median.

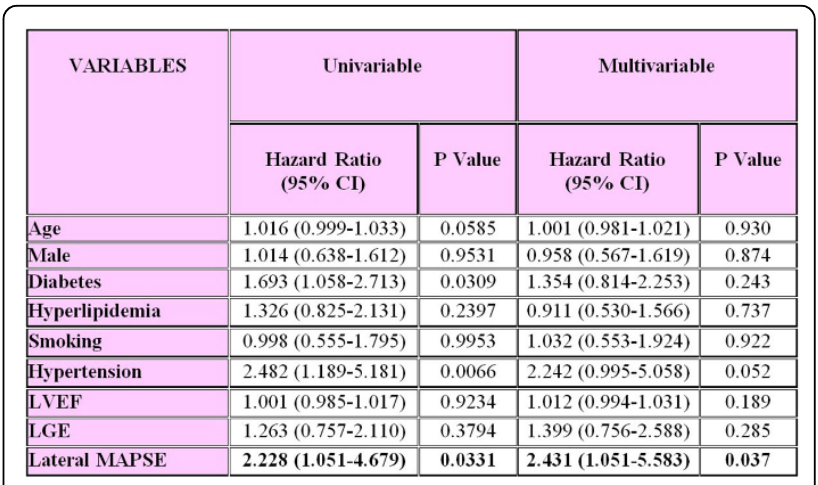

Figure 2 Univariable and multivariable predictors of MACE.

(Figure 1). After adjustment for established predictors (ejection fraction, age, sex, diabetes, hyperlipidemia, smoking, hypertension, late gadolinium enhancement) lateral 
MAPSE remained a significant independent predictor of $\operatorname{MACE}(\mathrm{HR}=2.43$ per $\mathrm{cm}$ decrease; $\mathrm{p}=0.037)$ (Figure 2$)$.

\section{Conclusions}

Longitudinal fiber dysfunction assessed with lateral MAPSE during cine-CMR is an independent predictor of MACE in patients with known or suspected coronary artery disease.

\section{Authors' details}

${ }^{1}$ Cardiology, University of Illinois at Chicago, Chicago, IL, USA. ${ }^{2}$ Medicine, University of Verona, Verona, Italy. ${ }^{3}$ Cardiology, Duke University, Durham, NC, USA.

Published: 27 January 2016

- Convenient online submission

- Thorough peer review

- No space constraints or color figure charges

- Immediate publication on acceptance

- Inclusion in PubMed, CAS, Scopus and Google Scholar

- Research which is freely available for redistribution 